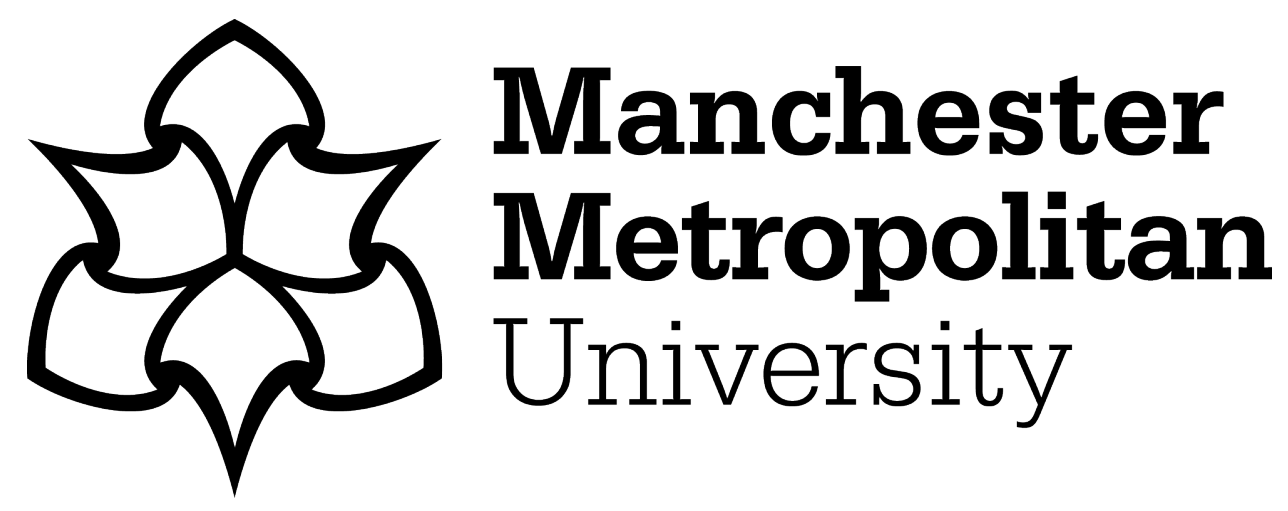

Parry, Sarah ORCID logoORCID: https://orcid.org/0000-0002-5666-1997, Atkinson, Cathy and Thomas, George (2019) Using concept mapping to understand motivational interviewing practice. Qualitative Research Journal, 20 (2). ISSN 1443-9883

Downloaded from: https://e-space.mmu.ac.uk/624545/

Version: Accepted Version

Publisher: Emerald

DOI: https://doi.org/10.1108/QRJ-04-2019-0038

Please cite the published version 


\title{
Using concept mapping to understand motivational interviewing practice
}

\author{
Cathy Atkinson and George Thomas \\ University of Manchester, Manchester, UK, and \\ Sarah Parry \\ Department of Psychology, Manchester Metropolitan University, Manchester, UK
}

\begin{abstract}
Purpose - Motivational interviewing (MI) has developed considerably since its inception, which may have led to diverse practice across contexts and differential understanding of core principles. Concept mapping is one potential method for offering insight into practitioner awareness, understanding and application of MI. The paper aims to discuss this issue.

Design/methodology/approach - In total, 29 professionals from a range of disciplines, including counselling, education and health, completed concept maps about MI, following brief training at the UK regional MI interest network. In total, 17 completed maps were submitted for analysis using quantitative and qualitative methods.
\end{abstract}

Findings - A total of 186 concepts and 175 propositional links were found within the 17 maps. The most commonly identified concepts were: change, empathy, collaboration, open-ended questions, affirmations, reflections, summaries (OARS), client centred and compassion. The concept maps also suggested differing levels of expertise across network members using concept mapping morphology classification. Research limitations/implications - The sample was small scale and located in one region of the UK. Maps were submitted anonymously meaning that participant data could not be matched to the maps. Practical implications - Concept mapping is a potentially useful method for auditing practice and developing skills in MI, as well as exploring participants' understanding of related concepts and therapeutic mechanisms.

Social implications - MI has a strong evidence-based across a variety of disciplines and contexts. Refining practitioner skills in MI has implications for the integrity of delivery, and improved client outcomes in areas such as substance use, health promotion and educational disaffection.

Originality/value - This is the first study to investigate concept mapping as a means of understanding MI practice. It has potential implications for training, monitoring, supervision and development in MI practice.

Keywords Practitioner, Motivational interviewing, Multidisciplinary, Practice development, Concept mapping, Conceptual understanding

Paper type Research paper

\section{Introduction}

Motivational interviewing

Motivational interviewing (MI) is a counselling style based on person-centred

philosophies

(Rogers, 1959). First introduced by Miller (1983) as an approach with clients whose drinking had become problematic, it is based on the premise that people are not always ready or motivated for behavioural change, and often feel ambivalent even in the face of concern from others (Miller and Rollnick, 2013). The approach has a large evidence base, and although initially developed from Miller and Rollnick's (1991) expertise in addiction and health care fields, it is now used across a wide range of different contexts (Miller and Moyers, 2017).

Although MI has been used for over 35 years, practice informs its theoretical development, meaning that as it has evolved, there have been significant changes to its core structure (Miller and Rollnick, 1991, 2002, 2013). Additionally, practice across contexts is potentially inconsistent, or sometimes based on outdated versions of MI (Atkinson and Woods, 2017). The most recent iterations identify both relational and technical factors of MI (Miller and Rose, 2009) and centre practice around a spirit of acceptance, compassion, 
evocation and partnership; key hierarchal processes of engaging, focusing, evoking and planning; and core skills using open-ended questions, affirmations, reflections and summaries (OARS). There is not yet theoretical coherence (Atkinson and Woods, 2017), although there is significant interest in the mechanisms which make it effective as an intervention (cf. Apodaca and Longabaugh, 2009, 2016). Furthermore, there is evidence that in order for MI to be integrated effectively into clinical practice, ongoing training and competency benchmarking may be needed (Hall et al., 2016). To date, there has been a dearth of literature exploring to what extent espoused practice is consistent with the central tenets of MI. Frost et al. (2018) recently conducted some of the first research which looked at MI across multi-professional contexts. Their systematic literature review not only identified differential client benefits within different areas of working but also identified a lack of definition, fidelity and standardisation within MI practice.

\section{Concept mapping}

Concept mapping is a method of diagrammatic representation akin to mind mapping (Buzan, 1990) and spider diagramming (Trowbridge and Wandersee, 1998) that enables both individuals and groups to externalise and explore their conceptual understanding of a given topic (Bressington et al., 2011; Hay and Kinchin, 2006, 2008). The construction of concept maps is prescriptive yet simple. First concepts are written in text boxes and organised hierarchically so that broad, inclusive concepts are at the top of a page and specific or exemplary concepts are at the bottom of the page. Then concepts are linked with labelled arrows to explain the nature of the association between concepts and make propositional statements. Whilst concepts may only be written once, any number of links can be made between them (Novak, 1998).

Concept maps can be constructed by individuals or groups of students. The method can be taught within $20 \mathrm{~min}$ and most students find that an additional 30 to $40 \mathrm{~min}$ provides sufficient time for construction around most topics (Hay and Kinchin, 2008). The pedagogical application of concept mapping is significant, in that teachers are able to: assess students' existing conceptual understanding (Hay and Kinchin, 2008); identify superficial or erroneous conceptual understanding that may hinder students' learning (Driver et al., 1994); group students according to their conceptual understanding (Kinchin et al., 2000); accurately plan lessons, lectures and seminars to extend and develop students' conceptual understanding (Hay and Kinchin, 2008); and make explicit their own personal networks of conceptual understanding from which lessons/ lectures/ seminars have been planned (Hay and Kinchin, 2008).

Concept mapping has been found to improve teacher-student dialogue (Kinchin, 2003) and facilitate collaborative group work (Kinchin and Hay, 2005). It also provides opportunity for student self-reflection and metacognition (Hay, Kinchin and Lygo-Baker, 2008; Novak, 1990) and is a useful revision tool (Kinchin et al., 2000). Furthermore, the repetition of concept maps over time (e.g. following a period of teaching) provides a visual learning record and enables temporal changes in students' conceptual understanding to be demonstrated (Hay, Kinchin and Lygo-Baker, 2008; Novak, 1990) and evaluated (Hay and Kinchin, 2008; Novak, 1998); it also demonstrates to what extent different aspects of a curriculum have been understood (Hay and Kinchin, 2008).

There are several quantitative methods for analysing concept maps. Some are objective and could be undertaken by non-experts in a given topic, such as counting the number of concepts, propositional links or hierarchical levels (Novak, 1990); or aggregated scoring protocols awarding different marks for these levels (Novak, 1998). Others are subjective and could only be undertaken by experts in a given topic. These include counting the number of key or expert concepts and expert scoring frameworks (Hay, Kinchin and Lygo-Baker, 2008; Hay, Kehoe, Miquel, Hatzipanagos, Kinchin, Keevil and Lygo-Baker, 2008). However, Bressington et al. (2011) and Kinchin et al. (2000) suggested that quantitative methods
Using concept mapping to understand MI practice 
have a tendency to overlook the richness of personal conceptual understanding, whereby qualitative methods for analysing concept maps focus on map morphology and enable student development to be categorised according to the cognitive structure of concept maps (see also Hay and Kinchin, 2006).

Upon first exploring a classification system to analyse concept map morphology, Kinchin et al. (2000) observed three distinct types of cognitive structure that have proved to be remarkably robust over time (Hay and Kinchin, 2006):

(1) spokes - a radial structure where all specific and/or exemplary concepts are linked to a single broad, inclusive, or "core" concept;

(2) chains - a linear structure where each concept is linked to other concepts in a sequence; and

(3) networks - a hierarchical and integrated structure of concepts.

Implicit within Kinchin et al.'s (2000) concept map classification system is the notion that as conceptual understanding becomes more integrated it moves from spoke, to chain, to network structures. Hay and Kinchin (2006) proposed that: spokes represent "undeveloped" conceptual understanding, indicative of learning in progress; chains represent "superficial" conceptual understanding, indicative of achievement, drive and task-oriented behaviour; and networks represent "expert" conceptual understanding, indicative of flexibility, creativity and the ability to learn.

Kinchin et al. (2000) highlighted that the cognitive structure of one's conceptual understanding around a given topic has implications for the further development. If one's conceptual understanding has a spoke structure, new concepts can be added by linking them to the core idea, but not to other concepts. If one's conceptual understanding has a chain structure, new concepts can be added by linking them to the end of the chain, but are unable to be added elsewhere in the chain without causing disruption to existing conceptual understanding. If one's conceptual understanding has a network structure, new concepts can be added by linking them to numerous existing concepts. Over time, Hay and Kinchin (2006) state that the addition of new concepts and/ or links to existing conceptual understanding can lead to the emergence of increasingly complex or different types of cognitive structure.

\section{Context for the research}

The Manchester Motivational Interviewing Network was set up to help professionals across multidisciplinary contexts develop their understanding and use of MI within professional practice; and to consider some of the issues related to fidelity and consistency of practice. The network involves universities and health care trusts within Greater Manchester, UK and advertises free meetings for professionals from a wide range of professional backgrounds with an interest in MI. In trying to gain a more comprehensive view of MI practice across disciplines and individuals, a concept mapping approach was used to establish a clearer picture of practitioner understanding and practice principles.

The short-term aim of the present study was to use concept mapping to represent the conceptual understanding of $\mathrm{MI}$ amongst helping professionals who attended the inaugural Manchester Motivational Interviewing Network event. The long-term aim was to evidence positive temporal change in attendees' conceptual understanding of MI as a result of subsequent network events, with the present study acting as a baseline.

\section{Method}

Sample

The inaugural Manchester Motivational Interviewing Network meeting held in June 2017 was advertised to helping professionals (including academics, practitioners and trainees) 
and university students with an interest in MI via mailing lists held by the University of Manchester, Manchester Metropolitan University and Greater Manchester Mental Health NHS Foundation Trust. Convenience sampling was undertaken during the event. Of the 29 people who attended the event and responded to the survey, a range of helping professions was represented, including educational psychologists (15: including one academic, two trainee educational psychologists and three assistant educational psychologists); psychotherapist (4); counselling psychologist (one trainee counselling psychologist); health psychologist (one academic); physiotherapist (1); and, probation officer (1). A number of university students (six) also attended. Data were collected from 17 participants who anonymously and voluntarily submitted their concept maps to the researchers for analysis. It should be noted that because of the anonymous submission, specific information for the volunteer participants is not available.

\section{Procedure}

The event began with the concept mapping exercise using Novak's (1990) approach to elicit attendees' understanding of MI and its application within their professional context. Guidance (in the form of a Microsoft PowerPoint presentation) and materials (e.g. A4 paper; sticky notes; pens) were provided; and attendees were given 30 min to complete their concept maps. Once the exercise had finished, attendees were provided with information about the research project and invited to leave their concept maps on a specified table at the end of the event if they wished to participate.

\section{Data analysis}

The 17 concept maps were analysed using both quantitative and qualitative methods. The total number of concepts and propositional links across the 17 concept maps were counted (Novak, 1990); and individual concept map morphologies were classified as spokes, chains, networks or unclassifiable (Kinchin et al., 2000).

\section{Ethics}

The university ethics committee deemed that ethical approval for this research project was not required as no personally identifiable data were collected (i.e. participants created their concept maps anonymously). Additionally, participants submitted their concept maps under their own volition, by leaving them on the table at the end of event. In total, 12 attendees exercised their right to either not complete the activity, or to not submit their concept maps for analysis.

\section{Results}

\section{Concepts and propositional links}

Across the 17 concept maps submitted for analyses, a total of 186 concepts and 175 propositional links were used by participants when they externalised and explored their conceptual understanding of MI and its application within their professional context, with a mean of 11 concepts and 10 propositional links per concept map. Of the 120 discrete concepts that were used by participants, the seven most common were: MI (17 references); change (12); empathy (7); collaboration (6); OARS (6); client/person centred (4); and compassion (3).

The concept of change, and indeed ambivalence about change is fundamental to MI. Indeed Miller and Rollnick (2013) defined MI as "a person-centred counselling style for addressing the common problem of ambivalence about change" (p. 29). That only 12 of the 17 respondents identified change as a core concept supports observations made at the
Using concept mapping to understand MI practice 
meeting, that some participants had little prior knowledge of MI, but had come along to find out more about it.

Smaller numbers of participants identified the underlying relational factor of empathy (Moyers and Miller, 2013), the emphasis on partnership or collaboration (Miller and Rollnick, 2013) and the OARS skills (Miller and Rollnick, 2013). Other notable concepts identified included MI's grounding in person-centred practice (Miller and Moyers, 2017; Rogers, 1959) and the compassion element of the quadratic spirit - other elements being acceptance, evocation and partnership (Miller and Rollnick, 2013).

\section{Concept map morphologies}

The morphology classifications of the concept maps submitted for analysis included six spoke, two chain, seven network and six unclassified. Overall, the distribution of concept map morphologies represented a dichotomy in terms of participants' conceptual understanding of MI and its application within their professional context. Roughly the same number of participants' concept maps were classified as spokes (undeveloped conceptual understanding indicative of learning in progress) or networks (expert conceptual understanding indicative of flexibility, creativity and the ability to learn), with very few concept maps classified as chains (superficial conceptual understanding indicative of achievement, drive and task-oriented behaviour (Hay and Kinchin, 2006)).

With reference to practice, these data indicated the need for developmental opportunities to increase the knowledge and confidence of less experienced attendees. As a direct result of this, the network organised a training day (Earnshaw et al., 2018) to upskill members and allow greater application of MI within practice.

\section{Case examples}

Illustrative examples of three concept map morphologies classified as a spoke, chain and network are presented in Figures 1-3. In Figure 1, the participant is aware of a number of concepts related to MI, which may have been partly informed by an introductory presentation at the network meeting. All of the OARS skills are evident, as are features of the MI spirit - empathy and collaboration (Miller and Rollnick, 2013). Also recognised is the person-centred nature of MI, developed from the work of Rogers (1959). However, as indicated by Kinchin et al. (2000), although all of the components are linked to the core concept (MI), none of them are linked to each other. Addition of new knowledge about MI could be easily assimilated as new spokes, without any interference to the overall "integrity"

Figure 1.

Concept map with a spoke morphology

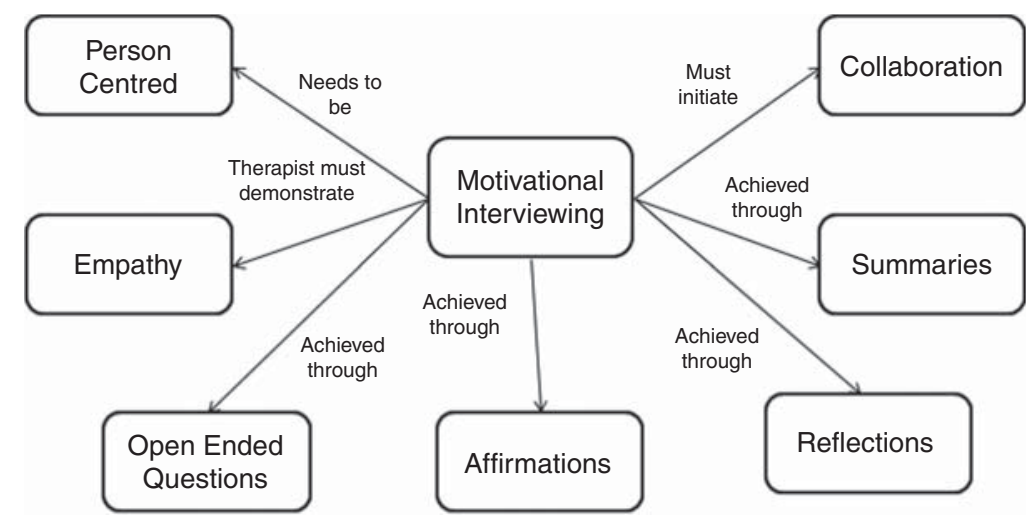




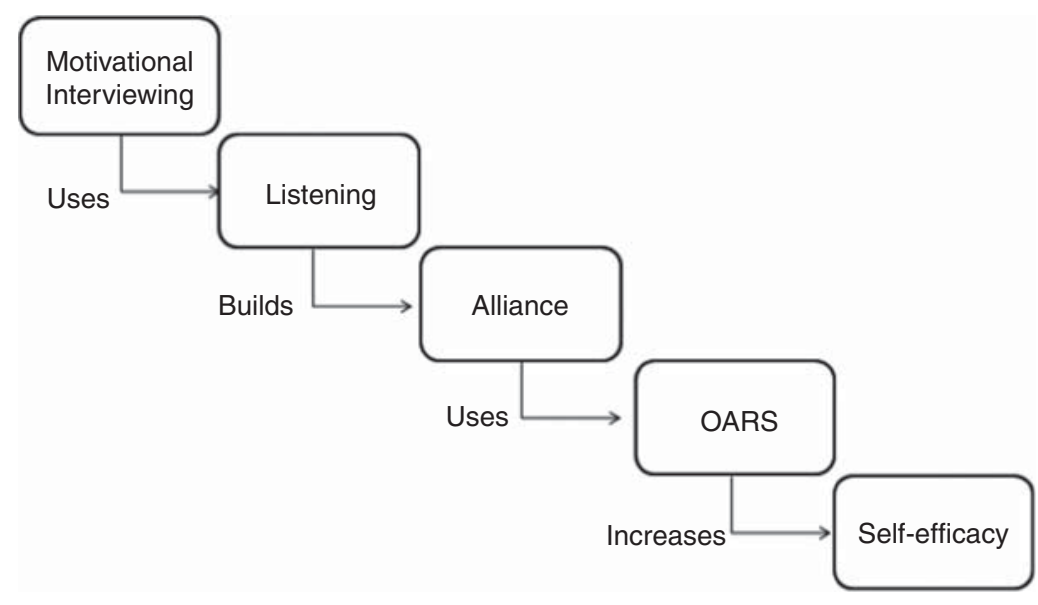

\section{Using concept mapping to understand MI practice}

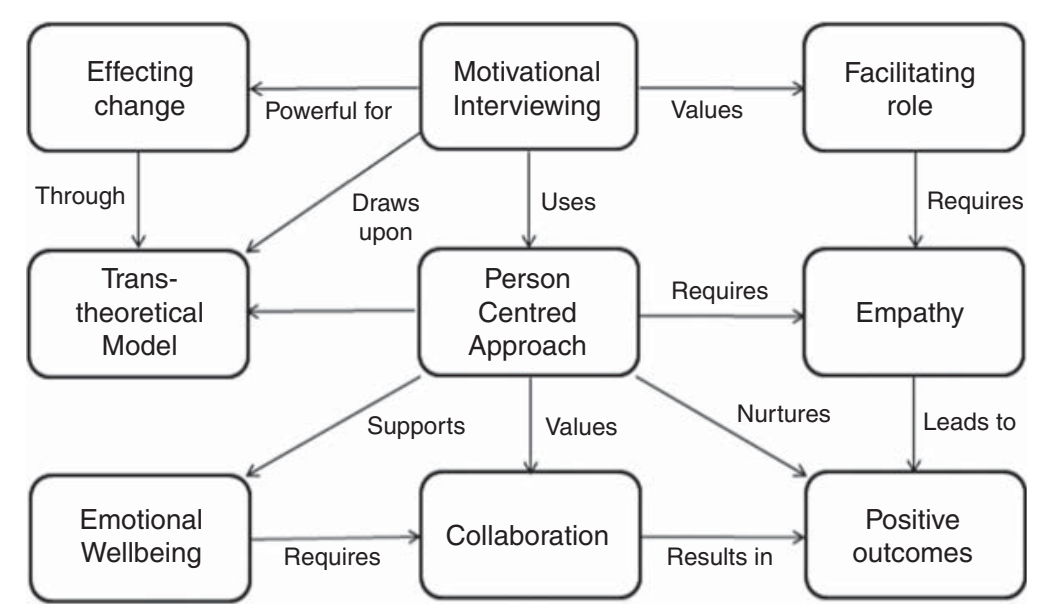

Figure 3.

Concept Map with a network morphology

of the map, while the absence of a "world view" about MI means that components can be added or lost, with little impact on conceptual understanding (Kinchin et al., 2000).

Figure 2 is indicative of chain morphology, in which the participant's concept of MI is demonstrated by a linear sequence of understanding (Kinchin et al., 2000). Specifically, its creator recognises that listening underpins the practice of MI (Miller, 2018) and is required for an effective alliance or partnership which forms part of the MI spirit (Miller and Rollnick, 2013). While the spirit is the philosophy behind MI, the OARS skills are a way of operationalising this, and indeed promote client self-efficacy, particularly through use of affirmation (Apodaca et al., 2016).

Kinchin et al. (2000) suggested a chain concept map is typical of a narrow view of a particular concept and that the lack of interactions and feedback mean that the map cannot cope with additional information. For example, the map above defines the practice of MI, but makes no reference to central premises, such as the notion of ambivalence about change, or the technical skills of eliciting change talk (reasons for, or intentions of change) or suppressing sustain talk (reasons not to change) (Miller and Rose, 2009). Introducing those 
concepts would mean that it would be difficult for the concept map to exist as a chain, and that the core understanding would need to be redeveloped.

Finally, Figure 3 represents the more complex network concept map. This map not only recognises a number of theoretical elements of MI, including a person-centred philosophy (Miller and Moyers, 2017; Rogers, 1959) and the drawing in of the transtheoretical model, a heuristic for readiness to change (Prochaska and DiClemente, 1982), but recognises connections between these elements. For example, on the right hand side, the creator has recognised that MI's facilitating role requires empathy and that this is fundamental to positive client outcomes (Moyers and Miller, 2013). Unlike Figures 1 and 2, Figure 3 recognises MI as multidimensional and complex, informed by both theoretical and philosophical approaches.

Figure 3 is consistent with Kinchin et al.'s (2000) description of complex interactions at different conceptual levels (p. 48). The integrity of a network concept map such as this is high, because new concepts can be integrated, without fundamental changes being required to its structure.

\section{Discussion}

Findings from this study indicate the potential usefulness of concept mapping at a number of levels. First they reveal how concept mapping can ascertain knowledge within a group. Specifically, the approach allowed understanding of which elements of MI were most prevalent in the minds of the network attendees, and how MI has been conceptualised across different professional groups, demonstrating the ability of concept maps to be a participant-centric snapshot of reflections on experience (Wheeldon and Faubert, 2009), in this case capturing variations between professionals. From a MI perspective, this indicated the absence of a consensus view about the most salient elements of the approach, which could be due to attendee inexperience in using the approach. It could also be as a result of MI practice developing differently within professional contexts, inconsistency in delivery, or a lack of theoretical stability (Atkinson and Woods, 2017; Frost et al., 2018). The concept maps were also indicative of the diverse needs of the group, in terms of recognising the need for training amongst many of the attendees, in order to upskill members to allow them to participate more fully.

In relation to both ascertaining knowledge and indicating learning priorities, concept mapping was helpful in achieving the short-term aim of the research. Interestingly, the process of concept mapping in groups supported by facilitated conversation, perhaps reducing reductionism and encouraging narrative reflection, appeared to elicit somewhat nuanced findings within and between professional groups around needs, variance and core concepts, which supports recently reported benefits of concept mapping as a methodology (Wheeldon, 2018).

Achieving the longer-term aim has been less straightforward. While it did not seem appropriate, and could have been potentially off-putting to ask attendees to link their concept maps to personal data at the very first meeting, it meant that personal development could not be tracked, negating researcher understanding of the impact on individuals' conceptualisation of MI, though network attendance. The vision of concept mapping being a benchmark for emerging group competence has been compromised by the fact that new members of the network have joined, and others have left during the six meetings, since June 2017, meaning that repeating the concept mapping exercise would involve a different sample.

The network, however, has plans to extend its training remit, in which case, concept mapping could be an ideal way of benchmarking initial competence, and assessing the impact of training. Although in infancy, concept mapping has been employed as a tool to explore and interpret skills training (Schuelke et al., 2009). Consequently, concept maps could also be a tool for competency benchmarking (Hall et al., 2016), alongside more practice-focused, but also more time-consuming and resource-intensive structured observation, typically undertaken using the Motivational Interviewing Treatment Integrity (MITI) scale (Moyers et al., 2016). 
It is noteworthy that the authors found the approach quick, straightforward and accessible, while participants reported, via an online survey at the end of the inaugural meeting, that they valued learning about the approach ("I really liked learning about concept mapping as well") and found it useful in conceptualising their knowledge ("It was helpful to use the concept map to clarify in my mind what I know and value about [MI]").

\section{Limitations and future research}

As described previously, details of the participants involved in the research are unknown, although the data can be contextualised within the wider sample of meeting attendees. The research was taken at a point in time, and makes no reference to training or experience prior to, or after the concept mapping activity. Repeating the activity at different time points with network members attending future planned training would potentially provide a picture of emerging knowledge and application of MI, both for both attendees and trainers.

The sample was small scale and located in a single geographic region of the UK. The diversity of practitioner contexts and previous experience meant that planning for the needs of the network, based on concept map data alone would have been problematic. However, within a single organisation, with a more coherent MI strategy, it could signpost professional development priorities much more clearly, and this is worthy of further investigation.

\section{Conclusion}

Concept mapping is an accessible method for exploring knowledge, particularly of complex phenomena - in this case, the counselling approach of MI, which is used across different contexts and has been subject to significant change (Miller and Rollnick, 1991, 2002, 2013). While in this instance, concept mapping allowed the authors to understand and plan for the needs of the network attendees, more sophisticated application could allow for personal development, competency benchmarking, and indeed theoretical development of MI.

\section{References}

Apodaca, T.R. and Longabaugh, R. (2009), "Mechanisms of change in motivational interviewing: a review and preliminary evaluation of the evidence", Addiction, Vol. 104 No. 5, pp. 705-715.

Apodaca, T.R., Jackson, K.M., Borsari, B., Magill, M., Longabaugh, R., Mastroleo, N.R. and Barnett, N.P. (2016), "Which individual therapist behaviors elicit client change talk and sustain talk in motivational interviewing?", Journal of Substance Abuse Treatment, Vol. 61, pp. 60-65, doi: $10.1016 /$ j.jsat.2015.09.001.

Atkinson, C. and Woods, K. (2017), "Establishing theoretical stability and treatment integrity for motivational interviewing", Behavioural and Cognitive Psychotherapy, Vol. 45 No. 4, pp. 337-350, doi: $10.1017 / \mathrm{S} 1352465817000145$.

Bressington, D.T., Wells, H. and Graham, M. (2011), “A concept mapping exploration of social workers' and mental health nurses' understanding of the role of the approved mental health professional", Nurse Education Today, Vol. 31 No. 6, pp. 564-570, doi: 10.1016/j.nedt.2010.10.034.

Buzan, T. (1990), The Mind Map Book, Penguin Books, London.

Driver, R., Squires, A., Rushworth, P. and Wood-Robinson, V. (1994), Making Sense of Secondary Science: Research into Children's Ideas, Routledge, London.

Earnshaw, P., Atkinson, C., Cordingley, L., Parry, S. and Thomas, G. (2018), "Introduction to Motivational Interviewing", Manchester Motivational Interviewing Network, Manchester, 28 June.

Frost, H., Campbell, P., Maxwell, M., Carroll, R.E.O., Dombrowski, U., Williams, B., Cheyne, H., Coles, E. and Pollock, A. (2018), "Effectiveness of motivational interviewing on adult behaviour change in health and social care settings: a systematic review of reviews", PLoS ONE, Vol. 155, pp. 1-39. 
Hall, K., Staiger, P.K., Simpson, A., Best, D. and Lubman, D.I. (2016), “After 30 years of dissemination, have we achieved sustained practice change in motivational interviewing?", Addiction, Vol. 111 No. 7, pp. 1144-1150, doi: 10.1111/add.13014.

Hay, D.B. and Kinchin, I.M. (2006), "Using concept maps to reveal conceptual typologies", Education + Training, Vol. 48 Nos 2/3, pp. 127-142.

Hay, D.B. and Kinchin, I.M. (2008), "Using concept mapping to measure learning quality", Education + Training, Vol. 50 No. 2, pp. 167-182.

Hay, D.B., Kinchin, I.M. and Lygo-Baker, S. (2008), "Making learning visible: the role of concept mapping in higher education", Studies in Higher Education, Vol. 33 No. 3, pp. 295-311.

Hay, D.B., Kehoe, C., Miquel, M.E., Hatzipanagos, S., Kinchin, I.M., Keevil, S.F. and Lygo-Baker, S. (2008), "Measuring the quality of e-learning", British Journal of Educational Technology, Vol. 36 No. 9, pp. 1037-1056.

Kinchin, I.M. (2003), "Effective teacher student dialogue: a model from biological education”, Journal of Biological Education, Vol. 37, pp. 110-113.

Kinchin, I.M. and Hay, D.B. (2005), "Using concept maps to optimize the composition of collaborative student groups: a pilot study”, Journal of Advanced Nursing, Vol. 51 No. 2, pp. 182-187.

Kinchin, I.M., Hay, D.B. and Adams, A. (2000), "How a qualitative approach to concept map analysis can be used to aid learning by illustrating patterns of conceptual development", Educational Research, Vol. 42 No. 1, pp. 43-57.

Miller, W.R. (1983), "Motivational interviewing with problem drinkers", Behavioural Psychotherapy, Vol. 11 No. 2, pp. 147-172, doi: 10.1017/S0141347300006583.

Miller, W.R. (2018), Listening Well: the Art of Empathic Understanding, WIPF \& Stock, Eugene, OR.

Miller, W.R. and Moyers, T.B. (2017), "Motivational interviewing and the clinical science of Carl Rogers", Journal of Consulting and Clinical Psychology, Vol. 85 No. 8, pp. 757-766, doi: $10.1037 / \mathrm{ccp} 0000179$.

Miller, W.R. and Rollnick, S. (1991), Motivation Interviewing: Preparing People to Change Addictive Behaviour, Guilford Press, New York, NY.

Miller, W.R. and Rollnick, S. (2002), Motivational Interviewing, Second Edition: Preparing People for Change, Guilford Press, New York, NY.

Miller, W.R. and Rollnick, S. (2013), Motivational Interviewing, Third Edition: Helping People Change, Guilford Press, New York, NY.

Miller, W.R. and Rose, G.S. (2009), "Toward a theory of motivational interviewing", The American Psychologist, Vol. 64, pp. 527-537, doi: 10.1037/a0016830.

Moyers, T.B. and Miller, W.R. (2013), "Is low therapist empathy toxic?", Psychology of Addictive Behaviors, Vol. 27 No. 3, doi: 10.1037/a0030274.

Moyers, T.B., Rowell, L.N., Manuel, J.K., Ernst, D. and Houck, J.M. (2016), "The Motivational Interviewing Treatment Integrity Code (MITI 4): rationale, preliminary reliability and validity", Journal of Substance Abuse Treatment, Vol. 65, pp. 36-42, doi: 10.1016/j.jsat.2016.01.001.

Novak, J.D. (1990), "Concept mapping: a useful tool for science education”, Journal of Research in Science Teaching, Vol. 27 No. 10, pp. 937-949.

Novak, J.D. (1998), Learning, Creating and Using Knowledge: Concept Maps as Facilitative Tools in Schools and Corporations, Lawrence Erlbaum Associates, Mahwah, NJ.

Prochaska, J.O. and DiClemente, C.C. (1982), "Transtheoretical therapy: toward a more integrative model of change", Psychotherapy: Theory Research and Practice, Vol. 19 No. 3, pp. 276-288.

Rogers, C.R. (1959), "A theory of therapy, personality and interpersonal relationships as developed in the client-centred framework", in Koch, S. (Ed.), Psychology: The Study of Science (Vol. 3), Formulations of the Person and the Social Context, McGraw-Hill, New York, NY, pp. 184-256. 
Schuelke, M.J., Day, E.A., McEntire, L.E., Boatman, P.R., Boatman, J.E., Kowollik, V. and Wang, X. (2009), "Relating indices of knowledge structure coherence and accuracy to skill-based performance: is there utility in using a combination of indices?", Journal of Applied Psychology, Vol. 94 No. 4, pp. 1076-1085, doi: 10.1037/a0015113.

Trowbridge, J.E. and Wandersee, J.H. (1998), "Theory-driven graphic organisers", in Mintzes, J.J., Wandersee, J.H. and Novak, J.D. (Eds), Teaching Science for Understanding: A Human Constructivist View, Academic Press, San Diego, CA, pp. 95-131.

Wheeldon, J. (2018), "Reflection/commentary on a past article: "framing experience: concept maps, mind maps, and data collection in qualitative research", International Journal of Qualitative Methods, doi: 10.1177/1609406918790673.

Wheeldon, J. and Faubert, J. (2009), "Framing experience: concept maps, mind maps, and data collection in qualitative research", International Journal of Qualitative Methods, Vol. 8 No. 3, pp. 68-83, doi: $10.1177 / 160940690900800307$.

\begin{abstract}
About the authors
Cathy Atkinson is Curriculum Director of the Doctorate in Educational and Child Psychology programme, and Senior Lecturer at the University of Manchester, UK. She is also Practis 19-1 ducational Psychologist, specialising in therapeutic approaches for students accessing alternativ wision for social, emotional and mental health difficulties. Her research interests include motivational interviewing, mental health promotion and the role of the educational psychologist in therapeutic work. Cathy Atkinson is the corresponding author and can be contacted at: cathy.atkinson@manchester.ac.uk

George Thomas is Academic and Professional Tutor on Doctorate in Educational and Child Psychology programme at the University of Manchester, and is also a practising educational psychologist at Bright Futures Educational Trust where he specialises in research- and evidence-based practice. George's research interests include mindfulness, motivational interviewing, mental health promotion and the role of the educational psychologist within multi-academy trusts.

Sarah Parry is prac $n \mathrm{~g}$ Clinical Psychologist and Senior Clinical Lecturer at Manchester Metropolitan University ${ }^{\top}$. Sarah's research interests include exploring voice hearing, related sensory experiences and multiplicity with young people and their parents/carers; alongside psychosocial and organisational interventions to support the wellbeing and self-care practices of professionals in caring roles.
\end{abstract}

